LEADING ARTICLE

\title{
When saliva meets acid: chemical warfare at the oesophagogastric junction
}

K E L McColl

Gut 2005;54:1-3. doi: 10.1136/gut.2004.047126

In the Western world at least, most upper gastrointestinal cancers now arise from the mucosa near to the oesophagogastric junction. Research into the mechanism of the development of adenocarcinoma at the oesophagogastric junction has mainly focused on the noxious effects of acid and bile. There is however an alternative concept for explaining the location of adenocarcinomas: the cancers are occurring at the anatomical site where saliva encounters acidic gastric juice and their interaction generates reactive nitrogen species which are potentially mutagenic and carcinogenic. At present, it is unclear whether the active nitrite chemistry is exerting detrimental effects on the surrounding tissue but it is important to investigate this possibility as it could reveal new ways of preventing and treating the high prevalence of disease occurring at this anatomical site

Correspondence to:

Professor K E L McColl,

University of Glasgow,

Section of Medicine,

Western Infirmary, 44

Church St, Glasgow G1 1

6NT, UK; k.e.I.mccoll@

clinmed.gla.ac.uk

Received 30 July 2004

Accepted for publication

17 August 2004
$\mathrm{T}$ here has been a remarkable change in the anatomical distribution of malignancy of the upper gastrointestinal tract over recent decades. The incidence of carcinoma of the mid and distal stomach has progressively fallen while that of adenocarcinoma of the distal oesophagus and proximal stomach has progressively increased. ${ }^{1-3}$ Consequently, in the Western world at least, most upper gastrointestinal cancers now arise from the mucosa near to the oesophagogastric junction.

The fall in incidence of carcinoma of the mid and distal stomach may be explained by the falling incidence of Helicobacter pylori infection and associated atrophic gastritis which are major risk factors for cancer at these sites. However, the more important and urgent question relates to the aetiology of the high and rising incidence of adenocarcinoma around the oesophagogastric junction.

Current wisdom is that adenocarcinoma of the distal oesophagus and oesophagogastric junction is due to the noxious effects of refluxing acidic gastric juice and possibly accompanying bile and duodenal juice on the oesophageal squamous mucosa. ${ }^{4}$ This induces columnar metaplasia of the distal oesophagus producing an epithelial phenotype resembling that of the gastric antrum, small intestine, or colon. When this metaplasia is extensive it is referred to as Barrett's oesophagus. Such metaplastic mucosa has a propensity to progress to dysplasia and adenocarcinoma. ${ }^{5}$

Gastric acid is a key factor in inducing damage to the squamous mucosa of the oesophagus. The increasing incidence of adenocarcinoma of the distal oesophagus may be explained by the fact that most people now maintain their ability to secrete gastric acid throughout life whereas in earlier generations acid secretion diminished with increasing age due to $H$ pylori infection. ${ }^{67}$ Most research into the mechanism of the development of adenocarcinoma at the oesophagogastric junction is focusing on the noxious effects of acid and bile, and these are likely to be important.

\section{"Gastric acid is a key factor in inducing damage to the squamous mucosa of the oesophagus"}

There is however an alternative or complementary concept for explaining the location of adenocarcinoma in the modern healthy acid secreting stomach. The cancers are occurring at the anatomical site where saliva encounters acidic gastric juice. In patients with reflux disease, saliva meets acid within the distal oesophagus which is where cancers occur in such patients. In patients without reflux, the cancers occur at the proximal cardia region of the stomach which is where saliva normally encounters gastric acid. The anatomical site where these two body fluids meet may be very important as their interaction generates reactive nitrogen species which are potentially mutagenic and carcinogenic. ${ }^{89}$ This nitrosative chemistry occurs due to the high concentration of nitrite in saliva and which originates mainly from dietary nitrate.

\section{ENTEROSALIVARY RECIRCULATION OF NITRATE}

The modern diet contains substantial quantities of nitrate, mainly derived from nitrogenous fertilisers. ${ }^{10}$ Nitrate is absorbed from the small intestine into the bloodstream. ${ }^{11}$ This circulating nitrate is supplemented by a smaller amount of endogenously produced nitrate, being the end product of enzymatically synthesised nitric oxide. Approximately $25 \%$ of all of this nitrate ingested or produced endogenously is actively taken up from the bloodstream by the salivary glands and secreted into the mouth. ${ }^{11-13}$ As a consequence, the concentration of nitrate in saliva is approximately 10-20 times higher than that in circulating blood (fig 1). ${ }^{14}$

\section{REDUCTION OF SALIVARY NITRATE TO NITRITE BY BUCCAL BACTERIAL}

The mouth has a very dense bacterial population. The dorsum of the tongue is particularly 


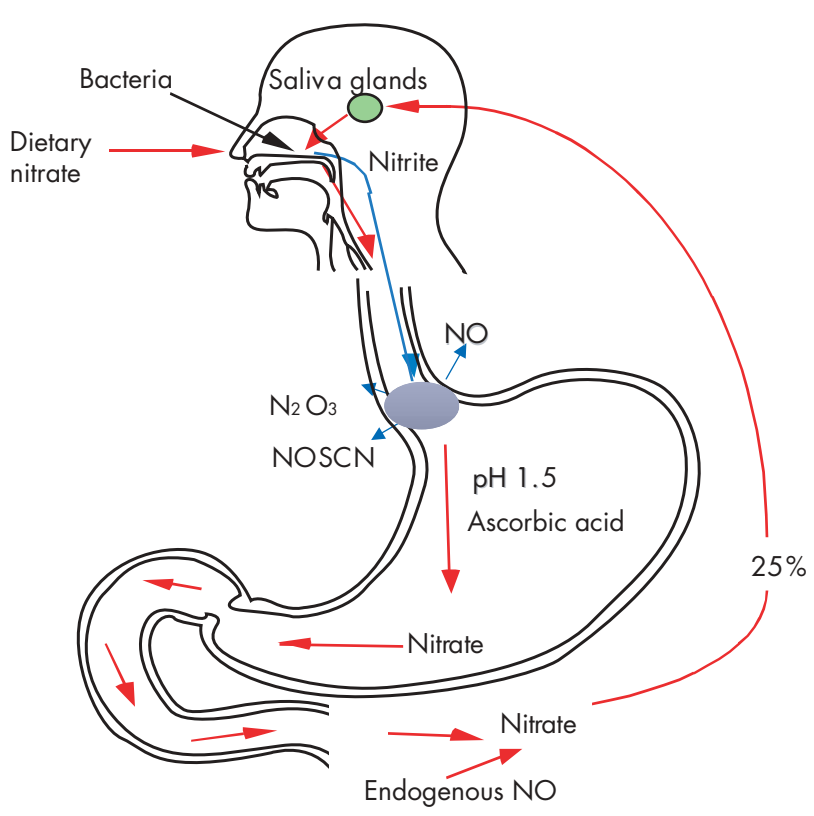

Figure 1 Of all the nitrate absorbed from the diet or produced endogenously, $25 \%$ is taken up by the salivary glands and secreted into the mouth. Bacteria on the dorsum of the tongue convert $10-90 \%$ of this nitrate in saliva to nitrite. When saliva is swallowed and meets acidic gastric juice it is converted to nitrosating species (that is, $\mathrm{N}_{2} \mathrm{O}_{3}$ and NOSCN) and by further reacting with ascorbic acid in gastric juice to nitric oxide (NO). In patients with reflux disease this chemistry occurs within the oesophagus where gastric refluxate mixes with saliva.

densely colonised by avid nitrate reducing bacteria. ${ }^{15-17}$ These organisms rapidly convert between $10 \%$ and $90 \%$ of the nitrate in saliva to nitrite. ${ }^{15-17}$ Consequently, human saliva contains very high concentrations of nitrite. Under fasting conditions, the nitrite concentration of saliva is 10$1000 \mu \mathrm{mol} / \mathrm{l}$ and this rises $2-5$-fold for several hours after ingesting nitrate containing foods. ${ }^{13} 1418$ Similar concentrations of nitrite are present throughout the of the oesophagus. ${ }^{19}$ Approximately $1.5 \mathrm{l}$ of saliva is prorieged every 24 hours and this nitrite rich fluid all passes down into the proximal stomach (fig l). ${ }^{20}$

\section{NITRITE CHEMISTRY OCCURRING WHEN SALIVA MEETS GASTRIC ACID}

When saliva encounters acidic gastric juice, nitrite within it is immediately converted to nitrous acid and nitrosating species, including $\mathrm{N}_{2} \mathrm{O}_{3}$ and $\mathrm{NO}^{+}{ }^{21}{ }^{22}$ The latter reacts with thiocyanate which is also secreted in high concentrations in saliva to form the particularly potent nitrosating species NOSCN. ${ }^{21}{ }^{22}$ These nitrosating species are able to react with a variety of organic nitrogenous compounds to generate potentially carcinogenic $N$-nitroso compounds. ${ }^{21}{ }^{22}$ For many years, $N$-nitroso compounds have been utilised to induce cancer of the oesophagus and stomach in experimental animals. ${ }^{23}$ In addition to their nitrosating potential, these nitrosating species can also induce oxidative stress manifest by the consumption of antioxidant vitamins and glutathione. ${ }^{24}$ It is the acidic $\mathrm{pH}$ of the gastric juice that converts the relatively inert nitrite present in saliva to these highly reactive nitrosating species (fig 1 ).

The main factor protecting against these nitrosating species generating $N$-nitroso compounds is ascorbic acid which is actively secreted in gastric juice. ${ }^{25}{ }^{26}$ Ascorbic acid reduces the nitrosating species to nitric oxide and in the process is oxidised to dehydroascorbic acid. ${ }^{19}{ }^{24-26}$ The highest concentration of nitrosating species within the upper gastrointestinal tract will occur at the anatomical site where (i) the ratio of nitrite to ascorbic acid is highest, (ii) there is an adequate thiocyanate concentration, and (iii) the $\mathrm{pH}$ is acidic. Recent studies indicate that in the healthy acid secreting stomach, the site most fulfilling those criteria and thus with the conditions most favouring generation of nitrosative species is the most proximal cardia region of the stomach where saliva first encounters acidic gastric juice. ${ }^{19}$

The reaction between saliva and acidic gastric juice not only produces nitrous acid and nitrosating species but also nitric oxide. ${ }^{27} 28$ Nitric oxide is produced by the reaction between the nitrosating species and the available ascorbic acid in gastric juice. ${ }^{8}$ Peak concentrations of nitric oxide generated in this way have again been observed in the cardia region of the stomach. ${ }^{29}$ Indeed, concentrations of nitric oxide measured at this site and derived from dietary nitrate are the highest recorded anywhere in the human body.

\section{"The oesophagogastric junction where saliva and gastric} acid meet is thus a site of very active luminal chemistry"

The oesophagogastric junction where saliva and gastric acid meet is thus a site of very active luminal chemistry. At this location, nitrite present in high concentrations in saliva is converted to nitrous acid, nitrosative species, and nitric oxide. In addition, the chemistry results in the local consumption of antioxidant vitamins present in gastric juice.

\section{POTENTIAL CLINICAL IMPLICATIONS OF THIS NITRITE CHEMISTRY}

Could this active nitrite chemistry which occurs when saliva meets gastric acid be contributing to the high incidence of metaplasia and neoplasia occurring at the oesophagogastric junction? At present we do not know. It will depend on whether the luminally generated nitrosative species or $N$-nitroso compounds produced by these species reach the adjacent epithelium in biologically significant amounts. The nitric oxide may be particularly important as it is highly diffusible and should be able to rapidly enter the adjacent epithelial cells. ${ }^{30}$

"Nitric oxide in high doses is known to be mutagenic"

Nitric oxide in high doses is known to be mutagenic. ${ }^{31}$ This is due to the fact that at high concentrations nitric oxide reacts with oxygen to form $\mathrm{N}_{2} \mathrm{O}_{3}$ which can damage DNA directly or indirectly via generation of $N$-nitroso compounds. ${ }^{32}$ Nitric oxide can also inactivate DNA repair enzymes such as $\mathrm{O}^{6}$-alkylguanine DNA alkyltransferase ${ }^{33}$ and DNA repair proteins such as formamidopyrimidine DNA-glycosylase. ${ }^{34}$ Again, whether any of these effects are produced by the luminally generated nitric oxide will depend on the amount reaching the adjacent epithelial cells.

\section{WHAT HAPPENS IN PATIENTS WITH REFLUX DISEASE?}

In patients with gastro-oesophageal reflux disease, the anatomical location where saliva meets acidic gastric juice is different from that in normal subjects. During gastrooesophageal reflux, the two juices meet within the distal oesophagus and consequently the active nitrosative chemistry occurs at that site. ${ }^{35}$ Simultaneous monitoring of oesophageal $\mathrm{pH}$ and nitric oxide shows that acid reflux episodes are often accompanied by sudden and very marked rises in nitric oxide. ${ }^{35}$ This is due to the acidity and ascorbic acid content of the gastric refluxate converting nitrite in the oesophageal lumen to nitric oxide. 
"The luminal nitrosative chemistry occurring in the oesophagus of patients with reflux disease may be particularly damaging"

The luminal nitrosative chemistry occurring in the oesophagus of patients with reflux disease may be particularly damaging. Acid reflux produces mucosa erosions and this will increase the exposure of epithelial cells to the nitrosative chemistry occurring within the oesophageal lumen. Erosive oesophagitis induces inflammation and cellular proliferation which is likely to make the epithelial cells more sensitive to luminally generated carcinogens. Animal models have shown that inflamed epithelium is more sensitive to the carcinogenic effects of $N$-nitroso compounds. ${ }^{36}$

\section{COULD NITRITE CHEMISTRY INDUCE GASTRO- OESOPHAGEAL REFLUX?}

It is also important to investigate whether the chemistry occurring when nitrite-rich saliva encounters acidic gastric juice might contribute to the aetiology of gastro-oesophageal reflux disease itself. Excessive local production of nitric oxide could explain most of the functional abnormalities associated with reflux disease. Nitric oxide lowers the tone of the lower oesophageal sphincter, ${ }^{37}$ impairs oesophageal clearance, ${ }^{38}$ and is the final mediator of transient lower oesophageal sphincter relaxations. ${ }^{39}$ To date, a single study has investigated whether administration of nitrate affects gastro-oesophageal reflux and demonstrated no effect. ${ }^{40}$ However, further studies are required.

\section{WHAT IS THE BIOLOGICAL BENEFIT OF THIS NITRITE CHEMISTRY?}

What is the reason for the healthy human body allowing this reactive nitrosating chemistry to occur when saliva meets acidic gastric juice? Complex processes are involved in bringing it about and it must confer some evolutionary benefit. Studies by Duncan et al have shown that this chemistry possesses antimicrobial activity. ${ }^{41}$ It therefore appears to be primarily designed to kill pathogenic microbes entering the body via the upper gastrointestinal tract. However, as with all legitimate targets, there is always the risk and indeed probability of collateral damage.

\section{CONCLUSIONS}

At present, it is unclear whether the active nitrite chemistry which occurs when saliva meets gastric acid at the oesophagogastric junction is exerting detrimental effects on the surrounding tissue. However, it is important to investigate this possibility as it could reveal new ways of preventing and treating the high prevalence of disease occurring at this anatomical site. These could include reducing nitrate intake and/or inhibiting the reduction of salivary nitrate to nitrite by buccal bacteria.

Conflict of interest: None declared.

\section{REFERENCES}

1 Powell J, McConkey CC. Increasing incidence of adenocarcinoma of the gastric cardia and adjacent sites. Br J Cancer 1990;62:440-3.

2 Botterweck AAM, Schouten $\sqcup$, Volovics A, et al. Trends in incidence of adenocarcinoma of the oesophagus and gastric cardia in ten European countries. Int J Epidemiol 2000;29:645-54.

3 El-Serag HB. The epidemic of esophageal adenocarcinoma. Haematol Oncol Clin N Am 2003;17:413-32.

4 Tytgat GN, Bartelink H, Bernards R, et al. Cancer of the esophagus and gastric cardia: recent advances. Dis Esophagus 2004;17:10-26.

5 Cameron AJ, OHt BJ, Payne WS. The incidence of adenocarcinoma in columnar-lined (Barrett's) esophagus. N Engl J Med 1985;313:857-9.

6 Katelaris PH, Seow F, Lin BPC, et al. Effect of age, Helicobacter pylori infection, and gastritis with atrophy on serum gastrin and gastric acid secretion in healthy men. Gut 1993;34:1032-7.
7 Feldman M, Cryer B, McArthur K, et al. Effects of aging and gastritis on gastric acid and pepsin secretion in humans: a prospective study. Gastroenterology 1996; 110:1043-52

8 lijima K, Fyfe V, McColl KEL. Studies of nitric oxide generation from salivary nitrite in human gastric juice. Scand J Gastroenterol 2003;38:246-52.

9 Moriya A, Grant J Williams C, Carswell A, et al. In vitro studies indicate that acid catalysed generation of $\mathrm{N}$-nitrosocompounds from dietary nitrate will be maximal at the gastro-oesophageal junction and cardia. Scand J Gastroenterol 2002;37:253-61

10 Forman D, Al-Dabbagh S, Doll R. Nitrates, nitrites and gastric cancer in Great Britain. Nature 1985;313:620-5.

11 Walker R. Nitrates, nitrites and $N$-nitrosocompounds: a review of the occurrence in food and diet and the toxicological implications. Food Addit Contam. 1990;7: 6, 717-68.

12 Gangolli SD, van den Brandt $\mathrm{P}$, Feron VJ, et al. Nitrate, nitrite and N-nitroso compounds. Eur J Pharmacol Environm Toxicol Pharmacol 1994;292:1-38.

13 Bartholomew B, Hill MJ. The pharmacology of dietary nitrate and the origin of urinary nitrate. Food Chem Toxicol. 1984;22: 10, 789-95.

14 McKnight GM, Smith LM, Drummond RS, et al. Chemical synthesis of nitric oxide in the stomach from dietary nitrate in humans. Gut 1997:40:211-14

15 Granli T, Dahl R, Brodin P, et al. Nitrate and nitrite concentrations in human saliva: variations with salivary flow-rate. Food Chem Toxicol. 1989;27: 10, 675-80.

16 van Maanen JM, van Geel AA, Kleinjans JC. Modulation of nitrate-nitrite conversion in the oral cavity. Cancer Detect Prev 1996;20:590-6.

17 Ruddell WSJ, Blendis LM, Walters CL. Nitrite and thiocyanate in the fasting and secreting stomach and in saliva. Gut 1977;18:73-7

18 Mowat C, Carswell A, Wirz A, et al. Omeprazole and dietary nitrate independently affect levels of vitamin $\mathrm{C}$ and nitrite in gastric juice. Gastroenterology 1999:116:813-22.

19 Suzuki H, lijima K, Moriya A, et al. Conditions for acid catalysed luminal nitrosation are maximal at the gastric cardia. Gut 2003;52:1095-101.

20 Documenta Geigy Scientific Tables, 6th edn. Manchester: Geigy Pharmaceutical Company, 1975.

21 Leach S. Mechanisms of endogenous N-nitrosation. In: Hill J, ed. Nitrosoamines: toxicology and microbiology. Chichester: Ellis Horwood, 1988:69-87.

22 Mirvish SS. Role of $\mathrm{N}$-nitroso compounds (NOC) and N-nitrosation in etiology of gastric, esophageal, nasopharyngeal and bladder cancer and contribution to cancer of known exposures to NOC. Cancer Lett 1995;93:17-48.

23 Sasajima K, Kawachi T, Matsukura N, et al. Intestinal metaplasia and adenocarcinoma induced in the stomach of rats by $\mathrm{N}$-propyl- $\mathrm{N}^{\prime}$-nitro- $\mathrm{N}$ nitrosoguanidine. J Cancer Res Clin Oncol 1979;94:201-6.

24 lijima K, Grant J, McElroy K, et al. Novel mechanism of nitrosative stress from dietary nitrate with relevance to gastro-oesophageal junction cancers. Carcinogenesis 2003;24(12): 1951-60.

25 Schorah CJ, Sobala GM, Sanderson M, et al. Gastric juice ascorbic acid effects of disease and implications for gastric carcinogenesis. Am J Clin Nutr 1991;53:287-93S.

26 Archer MC, Tannenbaum SR, Fan T-Y, et al. Reaction of nitrite with ascorbate and its relation to nitrosoamine formation. J Natl Cancer Inst 1975;54:1203-5.

27 McKnight GM, Smith LM, Drummond RS, et al. Chemical synthesis of nitric oxide in the stomach from dietary nitrate in humans. Gut 1997;40:211-14.

28 Lundberg JON, Weitzberg E, Lundberg JM, et al. Intragastric nitric oxide production in humans: measurements in expelled air. Gut 1994;35:1543-6.

29 lijima K, Henry E, Moriya A, et al. Dietary nitrate generates potentially mutagenic concentrations of nitric oxide at the gastroesophageal junction. Gastroenterology 2002;122:1248-57.

30 Chen B, Keshive M, Deen WM. Diffusion and reaction of nitric oxide in suspension cell cultures. Biophys J 1998;75:745-54.

31 Laval F, Wink DA, Laval J. A discussion of mechanisms of NO genotoxicity: implication of inhibition of DNA repair proteins. Rev Physiol Biochem Pharmacol 1997:131:175-91.

32 Wink DA, Fellisch $M$, Vodovotz $Y$, et al. In: Reactive oxygen species in biological systems. Gilbert DL, Coton CA, eds. New York: Kluwer Academic/ Plenum Publishers, 1999:245-91.

33 Liu L, Xu-Welliver M, Kanugula S, et al. Inactivation and degradation of $\mathrm{O}^{6}$. alkylguanine-DNA alkyltransferase after reaction with nitric oxide. Cancer Res 2002;62:3037-43.

34 O'Connor T, Graves RV, Murcia G, et al. Fpg protein of E. coli is a zinc finger protein whose cysteine residues have a structural and/or functional role. J Biol Chem 1993;268:9063-70.

35 Suzuki H, Henry E, McElroy K, et al. In: Barrett's esophagus acid reflux generates high luminal concentrations of nitric oxide derived from dietary nitrate. Gastroenterology 2003; 124(Supp 1): 1932.

36 Sugiyama A, Maruta F, Ikeno T, et al. Helicobacter pylori infection enhances $\mathrm{N}$-methyl-N-nitrosourea-induced stomach carcinogenesis in the Mongolian gerbil. Cancer Res 1981;58:2067-9.

37 Knudsen MA, Svane D, Tottrup A. Action profiles of nitric oxide, S-nitroso-Lcysteine, SNP, and NANC responses in opossum lower esophageal sphincter. Am J Physiol 1992;262:G840-6.

38 Simren M, Silny J, Holloway R, et al. Relevance of ineffective oesophageal motility during oesophageal acid clearance. Gut 2003;52:784-90.

39 Boulant J, Fioramonti J, Dapoigny $M$, et al. Cholecystokinin and nitric oxide in transient lower esophageal sphincter relaxation to gastric distention in dogs. Gastroenterology 1994;107:1059-66.

40 Bove M, Lundell L, Casselbrant A, et al. Effects of dietary nitrate on oesophageal motor function and gastro-oesophageal acid exposure in healthy volunteers and reflux patients. Digestion 2003;68:49-56

41 Duncan C, Li H, Dykhuizen R, et al. Protection against oral and gastroinestinal diseases: importance of dietary nitrate intake, oral nitrate reduction and enterosalivary nitrate circulation. Comp Biochem Physiol $1997 ; 118 A(4): 938-48$ 